

\title{
A Brief Analysis of Option Implied Volatility and Strategies
}

\author{
Zhou Heng \\ University of Adelaide, Adelaide, Australia
}

\begin{abstract}
With the implementation of reform of financial system and the opening-up of financial market in China, knowing and properly utilizing financial derivatives becomes an inevitable road. The phenomenon of B-S-M option pricing model underpricing deep-in/out option prices is called volatility smile. The substantial reasons are conflicts between model's presumptions and reality; moreover, the market trading mechanism brings extra uncertainties and risks to option writers when doing delta hedging. Implied volatility research and random volatility research have been modifying B-S-M model. Giving a practical case may let reader have an intuitive and in-depth understanding.

Keywords: financial derivatives, option pricing, option strategies
\end{abstract}

\section{Introduction}

Since the first standardized "exchanged-traded" forward contracts were successfully traded in 1864, more and more financial institutions and companies were starting to use financial derivatives not only for generating revenue, but also aiming for controlling the risk exposure. Currently, derivatives can be divided into four categories which are forwards, options, futures, and swaps. This essay will mainly focus on options and further discussing what causes the option's implied volatility and how to utilize implied volatility in a practical way.

\section{Causing the Implied Volatility}

Implied volatility plays an important role in valuing an option, and it is derived from Black-Scholes option pricing model. Several theories explained the reason.

\section{Market Trading Mechanism}

Basically, deep-out of money options have less probability to get valuable comparing with less deep-out of money options and at-the money options at expiration date. Therefore, generally deep-out of money options will be valued less than other options. It is becoming desirable for market investors because of its capacity to become valuable and relatively cheap. Overall, deep-out of the money options will have a higher implied volatility, moreover according to put-call parity theory, deep-in the money options will have a higher implied volatility as well.

\section{The Difference Between Reality and Assumption of Black-Scholes Model}

Under assumption of traditional Black-Scholes option pricing model, it assumes that return of financial underlying assets follows a normal distribution. Nevertheless, massive data analyzing illustrate that, in reality, the financial underlying asset's return follows a log normal distribution. Under log normal distribution, the

Zhou Heng, degree of bachelor, School of Business, University of Adelaide, Adelaide, Australia.

Correspondence concerning this article should be addressed to Zhou Heng, 6/112 Gilbert Street, South Australia 5000, Australia. 
probability of occurring an extreme value is greater than in the normal distribution. Hence, traditional B-S-M model will generally underestimate value of the deep-out of money option and deep-in the money options simultaneously.

\section{Case Demonstration}

Briefly BHP (BHP Billition Limited ) stock call options are used to give an example how to apply volatility arbitrage. Aiming to maximize profit, in general puts of the same strike price are priced higher than call options, including the stock trend speculation and the B-S-M framework, and the report will mainly observe out-of-money call options.

\section{Observations}

We observed BHP (BHP Billition Limited) Jun 30, 30.5, 31.5, 32, 32.5 five out-of-money BHP call options with the same time to expiration though varying strike prices from April 3rd, 2018 to April 18th, 2018. After calculating the implied volatility (IV) using a software, we graphed the plots and discovered a volatility skew initially, and higher strike price options have lower IV than lower strike price options. Such infers investors are expecting the probability of underlying price surpassing $\$ 30$ is on a decreasing trend. The phenomenon suggests an arbitrage opportunity as of the aforementioned B-S-M framework, where the calls would be highly demanded.



Figure 1. BHP option volatility skew on 3rd April, 2018.

On 3rd April, the calculated call option was overpriced by using mean reversion analysis. BHP stock average return historical volatility from 26th April, 2017 to 29th March, 2018 was 21.089\%, smaller than the current call's IV inferring the call being overpriced. As option is derivatives of its underlying, we can compare underlying assets historical volatility with option's implied volatility to determine whether it is fairly priced or not; the greater the difference between implied volatility and historical volatility, the greater profit from volatility arbitrage. 
Table 1

Comparing Implied Volatility and Historical Volatility(3rd April, 2018)

\begin{tabular}{ll}
\hline BHP Jun 18,30 & 3rd April, 2018 \\
\hline Implied volatility & 0.2157 \\
Historical volatility & 0.2109 \\
Difference & +0.0048 \\
\hline
\end{tabular}

\section{Strategy}

\section{Planning}

According to the mean reversion theory, price of an extreme overpriced or underpriced security will invert to its average price over a time, together with the speculations of the increasing trend of the recent stock price previously mentioned, hypothetically the assigned overpriced option should drop to average price. The strategy involves trading against the skew, when the option reverts to a fair price level, it will be bought back to earn profit.

The strategy of choice was delta hedging. To construct a delta neutral portfolio, we need to calculate the number of stocks by utilizing B-S-M model for hedging assigned call.

Notation:

Table 2

BSM Variables(3rd April, 2018)

\begin{tabular}{lllll}
\hline Stock price $\left(S_{0}\right)$ & Strick price $(X)$ & Risk free rate $\left(r_{f}\right)$ & Standard deviation $(\sigma)$ & Time to expiration $(T)$ \\
\hline$\$ 28.71$ & $\$ 30$ & $2.81 \%$ & 0.21557 & $\frac{76}{252}$ \\
\hline
\end{tabular}

$S_{0}, X, \sigma$, and $T$ are obtained from the AFR (2018); risk-free rate is from Australian bond. Noting $T$ is in trading days.

Calculations suggest each one call short should compensate with long 0.4052 stocks to hedge delta to zero. Thus 10,000 BHP Jun 18 calls were short and long 4,052 BHP stock as the opening position. Choice of broker was Westpac with transaction costs consisting of $0.11 \%$ gross value basis charged in stocks trading, $0.35 \%$ gross value basis charged, and $\$ 0.31$ per contract clear fees in options trading (Westpac, 2018).

$$
\begin{aligned}
\text { Initial investment cost } & =10,000 \times \$ 0.9(1-0.0035)-4,052 \times \$ 28.71(1+0.0011) \\
& =-\$ 107,492.39
\end{aligned}
$$

Implementation

(1) Week one portfolio value summary:

One week after, increasing in portfolio value $(\pi)$ calculation on 11th April is as follows. Current option price is at $\$ 1.14$ and BHP stock price is at $\$ 29.44$ per share. Call price increased from $\$ 0.9$ to $\$ 1.14$ and stock price increased $\$ 0.17$ per share. Stocks contribute to Week one profit due to initial position but greater call price consumes portion portfolio value.

$$
\begin{aligned}
\pi & =-10,000 \times(\$ 1.14-\$ 0.9)+4,052 \times(\$ 29.44-\$ 28.71) \\
& =\$ 557.96
\end{aligned}
$$

Portfolio adjustment:

The implied volatility has changed as follows: 
Table 3

Comparing Implied Volatility and Historical Volatility (11th April, 2018)

\begin{tabular}{ll}
\hline BHP Jun 18,30 & 11 th April, 2018 \\
\hline Implied volatility & 0.2158 \\
Historical volatility & 0.2109 \\
Difference & +0.0049 \\
\hline
\end{tabular}

On 11th April, the new stock price $\left(S_{l}\right)$ is $\$ 29.44$, and delta has become volatile demanding for adjustments. Applying BSM model:

Table 4

BSM Variables(11th April, 2018)

\begin{tabular}{lllll}
\hline Stock price $\left(S_{0}\right)$ & Strick price $(X)$ & Risk free rate $\left(r_{f}\right)$ & Standard deviation $(\sigma)$ & Time to expiration $(T)$ \\
\hline$\$ 29.44$ & $\$ 30$ & $2.81 \%$ & 0.2158 & $\frac{68}{252}$ \\
\hline
\end{tabular}

Extra 788 BHP long stock positions are required for maintaining the delta.

Adjustment cost $=-\$ 29.44 \times 788 \times(1+0.0011)$

$$
=-\$ 23,224.2
$$

(2) Week two portfolio value summary:

The implied volatility has changed as follows:

Table 5

Comparing Implied Volatility and Historical Volatility(18th April, 2018)

\begin{tabular}{ll}
\hline BHP Jun 18,30 & 18 th April, 2018 \\
\hline Implied volatility & 0.1905 \\
Historical volatility & 0.2109 \\
Difference & -0.0204 \\
\hline
\end{tabular}

The call price and stock price at 18 th April are $\$ 1.24$ and $\$ 30.70$ respectively. The profit is based on current position with new price (write 10,000 calls and long 4,840 stocks):

$$
\begin{aligned}
\pi & =-10,000 \times(\$ 1.24-\$ 0.73)+4,840 \times(\$ 30.70-\$ 28.88) \\
& =\$ 659.60
\end{aligned}
$$

Despite call price increased significantly offsetting returns from stocks, a $\$ 659.60$ gain was realized.

To close out, the inverse sequence of operation takes place. Originally, the portfolio consists of short 10,000 calls and long 4,840 stocks, and amendments are as followed: long back 10,000 calls at $\$ 1.24$, selling out 4,840 stocks at $\$ 30.07$ while paying off transaction fees. Profit calculation is shown below:

$$
\begin{aligned}
\pi & =-10,000 \times \$ 1.24(1-0.0035)+4,840 \times \$ 30.07(1-0.0011)-10,000 \times \$ 0.13 \\
& =\$ 131,635.30
\end{aligned}
$$

\section{Trading Profits Summary}

Initially, $\$ 107,492.40$ was invested, receiving $\$ 131,635.30$ in the end. During the first trading week, $\$ 557.96$ was realized; in first date of second week adjustment was made costing $\$ 23,224.2$, concluding with a gain of $\$ 659.60$. Total return is:

$$
\pi=-107,492.4-23,224.2+131,635.3=\$ 918.7
$$




$$
\begin{aligned}
\pi & =-\$ 107,492.40-\$ 23,224.20+\$ 131,635.3 \\
& =\$ 918.7 \\
\frac{918.7}{130,716.6} & =0.7 \% \text { yield }
\end{aligned}
$$

The whole trading yielded $0.7 \%$ profit over two weeks.

\section{Evaluation}

\section{Overlook}

Delta hedge and volatility arbitrage strategies earned a $0.7 \%$ return in two weeks which is relatively insignificant to professionals. Theoretically, delta hedge portfolio would provide a risk-free return plus arbitrage profit, based on the option price volatility and inherent drawbacks of delta hedge strategy. The IV graph plot for each option declined on varying scale. The general decline is likely the effect of lost in time value, thus option value decreases, compensating IV would also fall. Though further evaluation then suggests an anomaly, on 18th April the call had an IV of 0.1905, lower than the historical volatility of 0.0204, contrasting to its price of $\$ 1.04$ being higher than our initial option price with higher implied volatility. The phenomenon breaches the theory, an unanticipated incident in past time, inducing $\$ 3,400$ loss.

\section{Improvement for Strategy}

By hind side, knowing option price would rise after two weeks; the strategy would long 10,000 calls waiting to short them at a higher price two weeks later, simultaneously short sell 100,000 delta numbers of BHP stocks to reduce calls exposure risk.

\section{Delta Hedge Strategy Assessment}

The intention was to identify an overpriced option, write it first, and then buy back to gain arbitrage profit; such provids hedging exposure risk from short positions and is a simple strategy to execute. Calculation based on real data illustration of our delta strategy is profitable though results suggest otherwise. Profit from delta hedge is smaller than risk-free return, mainly due to the absence of hedging Greeks neutral, e.g., Rho neutral, Vega neutral, Theta neutral, and Gamma neutral. Moreover, delta hedge only hedges against minor changes in underlying asset price, thus in practice it requires constant adjustment and often should be accompany with other Greeks for a more practical strategy.

\section{Improvement on Delta Hedge Portfolio}

A Gamma neutral portfolio could compliment the above mentioned drawbacks. Gamma neutral represents delta on a larger scale, thus more suited for larger underlying movements. To achieve such, the portfolio gamma and delta value are required then applying the formula $w_{T}=\frac{-\gamma}{\gamma_{T}}$ then $\Delta_{T} \times w_{T}$ to buy or sell the number of shares to obtain delta neutrality, or simply hedge the gamma of two options accordingly to a ratio.

\section{Relative Volatility vs. Absolute Volatility}

It is popular to utilize volatility-orientation strategies to make profits when trading options in the markets. Volatility smile and Gamma are both volatility-orientation strategies for the purpose.

A similarity between the two strategies is that they both use volatility as measurements. Volatility smile is the plot of the implied volatility of an option with the same maturity as a function of its strike price (Hull, 2012, 
p. 409). Volatility smile defines the relationships between implied volatility and strike price, enabling traders to use volatility smile to set option prices (Hull, 2012, p. 420). The Gamma of a portfolio of options is the rate of portfolio's delta change with the change of underlying assets price (Hull, 2012, p. 389). When Gamma is calculated, the equation is $\gamma=\frac{\mathrm{e}^{-\mathrm{d}_{1}^{2} / 2}}{\mathrm{~S}_{0} \sigma \sqrt{2 \pi \mathrm{T}}}$. The value of volatility $(\sigma)$ is used for this equation.

In contrast, Delta and Gamma hedging are both based on the assumption that underlying assets' volatility is constant whilst volatility smile/skew assumes a dynamic movement. The Greek's volatility is more likely to be historical volatility because it is calculated based on recent data similar to an absolute volatility value. In practice, the volatilities are changing frequently and traders also need to constantly rebalance the portfolios to maintain delta neutrality. Such may seem more practical to use relative volatility of skew/smile to depict non-log normality trends.

\section{Conclusion}

As time flows, financial market substantially plays a more significant role in an economy. Especially for current Chinese economy, as the world's second largest economy, financial market scale also ranks third in the world. However, the financial internationalization level, regulation level, and business development level cannot satisfy the current demand of Chinese economy. Moreover, it also does not accord with China's robust economic growth, the increasing number of middle classes, wealth increases, and ageing populations. Therefore, comprehensively promoting financial reform and domestic market internationalization is an inevitable trend. Knowing financial derivatives and introducing financial derivatives into Chinese market become a necessary way in the future.

\section{References}

AFR. (2018a). Australian Share market trading data for Tuesday. Retrieved on April 3, 2018 from http://www.afr.com/share-tabl es

AFR. (2018b). Australian share market trading data for Monday. Retrieved on April 9, 2018 from http://www.afr.com/share-tabl es

AFR. (2018c). Australian share market trading data for Monday. Retrieved on April 16, 2018 from http://www.afr.com/share-tabl es

Hull, J. (2012). Options, futures, and other derivatives (8th ed.). UK: Pearson Education.

Icngateway. (2018). BHP-South Flank iron ore project. Retrieved on 6th April, 2018 from https://gateway.icn.org.au/project/39 05/bhp-south-flank-iron-ore-project

McKinnon, S. (2017). BHP begins early work at \$US3.2b South Flank project. The West Australian. Retrieved on 6th April, 2018 from https://thewest.com.au/business/mining/bhp-begins-early-work-at-us32b-south-flank-project-ng-b88518020z

Statistia. (2018) BHP billiton-Statistics \& facts. Retrieved on 6th April, 2018 from https://www.statista.com/topics/3401/bhp-bill iton

Trading Economics. (2018). Australia government bond 10Y. Retrieved on 3rd April, 2018 from https://tradingeconomics.com/aus tralia/government-bond-yield

Westpac (2018). View fees \& charges. Retrieved on 4th April, 2018 from https://onlineinvesting.westpac.com.au/Public/FeesAnd Charges/FeesAndCharges.aspx

Yahoo Finance. (2018) BHP billiton limited (BHP.AX). Retrieved on 3rd April, 2018 from https://au.finance.yahoo.com/quote/BH P.AX/history?p=BHP.AX 